\title{
PERCEPTIVE-AUDITORY PERCEPTION OF THE MATERIAL OF DIFFERENT KINDS: EXPERIMENTAL RESEARCH
}

\author{
Marina V. Khitina \\ Moscow State Linguistic University, Moscow, Russian Federation
}

\begin{abstract}
The article describes experiments carried out at the Department of Applied and Experimental Linguistics for a prolonged period under scientific supervision of Ph.D., Sc.D., prof. Rodmonga Potapova. Problems solved in the course of the research as well as the most conspicuous results of auditory perceptual experiments are presented. An annotated database of Russian spoken language containing phonograms of reading and speaking (monologues, dialiogues, and polylogues) formed in MS Access DBMS was used, which ensured the most efficient data representation and logic of the research. The database consists of several tables containing information about the speakers ( $\mathrm{N}=72)$, namely, biographical data, physioanthropological characteristics, information on individual speech peculiarities, and lists of phonograms containing the speech of each speaker. Auditory perception of the said materials under different listening conditions (white and pink noise, different signal to noise ratios) was analyzed. The experiments involved different groups of auditors, all of them filled special questionnaire before taking part in the research, so that all peculiarities of their perception could be taken into account. Difference in perception of phonograms that included reading and speaking, monologues, dialogues and trilogues were analyzed, probability of perception of different spoken language units was estimated.

Methods of analysis and assessment of the data obtained are proposed, interpretation of the results is given. Special attention is paid to semantic perception of texts that the auditors recovered basing on the speech units perceived, which included also the detection of the topics of the texts. For the assessment of the latter data a special scale was devised which included overall correctness evaluation, possible modifications and substitutions. Alternative topic formulations proposed by the auditors were carefully analyzed. While interpreting the data on speech perception in white noise, topic formulations obtained were grouped into clusters, analyzed from the point of view of their formal structure and parts of speech used. The assessment of semantic perception of the recovered texts was performed using the approach proposed by T.M. Dridze, which proved efficient with regard to the specific material used in this research and allowed to estimate what the auditors perceive as the most significant information.

Key words: perception, sense perception, perceptive-auditory experiment, monologue, dialogue, polylogue.

Citation. Khitina M.V. Perceptive-Auditory Perception of the Material of Different Kinds: Experimental Research. Vestnik Volgogradskogo gosudarstvennogo universiteta. Seriya 2, Yazykoznanie [Science Journal of Volgograd State University. Linguistics], 2017, vol. 16, no. 2, pp. 109-115. (in Russian). DOI: https://doi.org/ 10.15688/jvolsu2.2017.2.11.
\end{abstract}

УДК 81’33:612.858.7

Дата поступления статьи: 23.03.2017

ББК 81.1

Дата принятия статьи: 28.04.2017

\section{ПЕРЦЕПТИВНО-СЛУХОВОЕ ВОСПРИЯТИЕ МАТЕРИАЛОВ РАЗНОГО ВИДА: ЭКСПЕРИМЕНТАЛЬНЫЕ ИССЛЕДОВАНИЯ}

\author{
Марина Викторовна Хитина \\ Московский государственный лингвистический университет, г. Москва, Российская Федерация
}

Аннотация. В статье описываются эксперименты, которые проводились на кафедре прикладной и экспериментальной лингвистики в течение длительного времени под научным руководством доктора филологических наук, профессора Р.К. Потаповой. Представлены наиболее значимые результаты перцептивно-слуховых экспериментов по восприятию аудиторами различных материалов на русском языке: фонограмм из 
аннотированной устно-речевой базы данных - УРБД, также разработанной на кафедре и содержащей чтение текстов, спонтанное говорение (монологи, диалоги, трилоги) на выбранные дикторами общеизвестные темы. Для реализации УРБД использована система управления базами данных СУБД Access, позволяющая эффективно подготовить представление данных и определить логику работы. УРБД состоит из таблиц, содержащих анкетные сведения о дикторах, информацию об их физиоантропологических характеристиках и о характеристиках речи каждого диктора $(\mathrm{N}=72)$, а также сведения о файлах фонограмм. Анализируются особенности восприятия указанных материалов в разных режимах прослушивания (розовый и белый шумы, различные соотношения сигнал / шум). В эксперименте участвовали различные группы аудиторов, прошедших предварительное анкетирование. Анализировались отличия восприятия материалов чтения и говорения, сравнивались результаты восприятия монологов, диалогов, трилогов, определялись возможности опознания речевых единиц в различных условиях.

Предлагаются методы анализа и оценки полученных данных, дается их интерпретация. Особое внимание уделяется смысловому восприятию текстов, восстановленных аудиторами на основе зафиксированных при прослушивании речевых единиц, и определению темы прослушанных текстов. Для анализа полученных данных по определению тем текстов была разработана специальная шкала оценки, учитывающая правильность / неправильность определения темы текста, возможные модификации и замены. При прослушивании диалогов в белом шуме и определении тем проводились группировка полученных формулировок, анализ их формальной организации, квалификация использованных речевых единиц с точки зрения частеречной принадлежности. Оценка смыслового восприятия восстановленных аудиторами текстов проводилась с помощью методики Т.М. Дридзе, которая оказалась эффективной при работе со специфическим материалом и позволила выявить, какую информацию аудиторы считают наиболее значимой.

Ключевые слова: восприятие, смысловое восприятие, перцептивно-слуховой эксперимент, монолог, диалог, полилог.

Цитирование. Хитина М. В. Перцептивно-слуховое восприятие материалов разного вида: экспериментальные исследования // Вестник Волгоградского государственного университета. Серия 2, Языкознание. 2017. - T. 16, № 2. - C. 109-115. - DOI: https://doi.org/10.15688/jvolsu2.2017.2.11.

\section{Введение}

На кафедре прикладной и экспериментальной лингвистики Московского государственного лингвистического университета в течение многих лет проводились эксперименты по перцептивно-слуховому восприятию материалов различного вида. Исследования осуществлялись под научным руководством доктора филологических наук, профессора Р.К. Потаповой по заказам Министерства образования и науки и других ведомств. Результаты проведенной работы представлены в различных публикациях участников проектов. В данной статье описаны некоторые наиболее значимые экспериментальные исследования.

\section{Экспериментальные исследования}

Проиедура экспериментов. Для проведения подобных исследований была разработана аннотированная устно-речевая база данных (УРБД) [Абрамов и др., 2010б], созданная на материале русского языка. Она содер- жала более тысячи фонограмм в записи от 72 дикторов (мужчин и женщин разного возраста, образования, социального положения и т. д.). В качестве непосредственного материала были избраны чтение и говорение (монологи, диалоги, трилоги) на общеизвестные темы. Для организации УРБД была использована СУБД MS Access. УРБД состояла из таблиц, содержащих анкетные данные дикторов, информацию о файлах фонограмм, сведения о физиоантропологических характеристиках дикторов (соответствующие замеры были проведены заранее). Кроме того, была представлена информация о характеристиках речи каждого диктора, подготовленная на основании экспертных оценок.

Эксперименты по перцептивно-слуховому восприятию материала проводились в затрудненных условиях (на фонограммы был наложен розовый или белый шум, причем были представлены различные соотношения сигнал / шум).

Участники экспериментов. В экспериментах принимали участие различные группы аудиторов, прошедших предварительное 
анкетирование и имеющих опыт работы с зашумленным материалом [Абрамов, Потапова, Хитина, 2010а].

Результаты экспериментов.

1. Эксперименты по восприятию чтения и говорения в условиях белого шума (соотношение сигнал / шум 0 дБ и 10 дБ) показали, что аудиторы гораздо хуже воспринимают читаемые тексты, а не спонтанные высказывания.

2. Последующие эксперименты по восприятию монологов, диалогов и трилогов в условиях розового шума (соотношение сигнал / шум 0 дБ, -6 дБ, -12 дБ) показали, что аудиторы лучше воспринимают диалоги (трилоги), чем монологи. Данные наблюдения были подтверждены результатами, полученными при прослушивании фонограмм в белом шуме (соотношение сигнал / шум 0 дБ, 10 дБ) [Абрамов, Потапова, Хитина, 2011; Потапова, Потапов, Хитина, 2010a; Потапова, Потапов, Хитина, 2010б; Потапова, Хитина, 2015; Хитина, 2012]. Кроме того, следует отметить, что среди правильно воспринятых аудиторами речевых единиц (слов и словосочетаний) преобладали имена существительные, в меньшей степени были представлены глаголы. С улучшением условий прослушивания распределение слов, относящихся к различным частям речи, приближалось к их соотношению в естественной речи.

3. Особый интерес в проведенных экспериментах представляло смысловое восприятие текстов фонограмм [Потапова, Потапов, Хитина, 2010в]. В задачу аудиторов входила не только фиксация воспринятых на слух речевых единиц. Они должны были на основе полученных списков слов попытаться восстановить исходный текст. Как показали эксперименты (в розовом и белом шумах), аудиторы смогли справиться с этой задачей. Сложность представляли только самые трудные для восприятия режимы прослушивания, где у аудиторов было минимальное количество зафиксированных слов, зачастую служебных, что не давало возможности создать на их основе какой-либо текст.

Для оценки смыслового восприятия восстановленных текстов была использована методика Т.М. Дридзе [Дридзе, 1976]. Анализ полученных результатов прослушивания монологов в розовом шуме показал, что применение данной методики для анализа специфического материала имеет определенные перспективы. Ее использование дает возможность оценить, что аудиторы выделяют в качестве основной информации. Так, полученные данные показывают, что при плохих условиях прослушивания аудиторы на основании воспринятых единиц отмечают предикации 1-го порядка (терминология Т.М. Дридзе). При улучшении условий прослушивания аудиторы отмечают дополнительно предикации 2-го и 3-го порядков. Данные выводы были подтверждены на материале диалогов, подаваемых в условиях белого шума (дипломные работы А. Страховой и В. Мартиросян, выполненные под руководством автора статьи) [Хитина, 2014; Хитина, 2015а; Хитина 2015б].

4. При проведении экспериментов важной задачей для аудиторов было определение темы текста (дискурса), представленного на зашумленных фонограммах. Аудиторы, зафиксировав воспринятые слова, должны были сформулировать тему текста. Как показали эксперименты, проведенные в розовом и белом шумах (при различном соотношении сигнал / шум), в большинстве случаев эту задачу аудиторы успешно решали (за исключением наихудших режимов прослушивания). При этом обнаружилось, что в некоторых случаях аудитор не зафиксировал при прослушивании ни одной речевой единицы, однако тему текста определил правильно; и наоборот, число воспринятых речевых единиц могло быть значительным, но у аудитора возникали сложности при определении темы текста (возможно, это связано с наличием в полученных списках как речевых единиц, относящихся к глобальной теме, так и речевых единиц, относящихся к локальным темам) [Гудков, 2016; Потапова, Потапов, Хитина, 2011; Саакян, 2014; Хитина, 2017].

Поскольку эксперименты проводились в шумах разного вида, целесообразно выделить некоторые общие закономерности восприятия материалов разного вида. Для оценки правильности определения темы текста была предложена специальная шкала: тема определена / не определена; если определена, то правильно или неправильно. Учитывались также возможные замены глобальной темы 
на локальную, локальной на глобальную и встретившиеся модификации: сужение или расширение темы воспринятого текста [Гудков, 2016; Саакян, 2014]. В ходе исследования использовалось довольно распространенное и весьма общее определение темы (это то, о чем говорится).

Анализ восприятия текста и определения его темы в розовом шуме (при соотношении сигнал / шум -14 дБ, -16 дБ, -18 дБ и -20 дБ) показывает, что были определены глобальная и в большинстве случаев локальные темы монологов [Саакян, 2014; Хитина, 2015a; Хитина 2015б]. Шкала оценки была уточнена: глобальная тема определена правильно, близко по смыслу, неправильно; локальная тема / темы определены полностью, частично; больше половины тем, половина, меньше половины тем. Оценивались и взаимные замены глобальной и локальных тем. В ходе эксперимента была отмечена прямая зависимость между уровнем зашумления и правильностью определения глобальной и локальных тем монологов.

Исследования определения тем текстов по результатам прослушивания диалогов из УРБД в белом шуме (соотношение сигнал / шум 0 дБ, 10 дБ и 20дБ) предполагали осуществление группировки полученных от аудиторов формулировок. Группам информантов было предложено осуществить и обосновать свое разбиение, а также дать названия для каждой из выделенных групп [Гудков, 2016]. Предварительно все предложенные определения были оценены по шкале соответствия / несоответствия заявленной теме и установлены возможные модификации. Кроме того, был проведен анализ формальной организации формулировок (отдельное слово, словосочетание, предложение) и установлены части речи, которые были задействованы в анализируемых формулировках. Предварительные результаты показывают, что в среднем количество опознанных тем при трех режимах прослушивания составляло 90 \%. Примерно в половине случаев тема текста была определена правильно, но при этом довольно часто отмечались случаи сужения темы. В рассматриваемых формулировках чаще других были задействованы имена существительные, а сами формулировки были представлены в ос- новном отдельными словами (предложения встречались очень редко). Важно отметить, что аудиторы, определив глобальную тему, далее могли делать уточнения, конкретизировать отдельные положения текста.

\section{Заключение}

Представленный краткий обзор основных видов исследований по восприятию звучащей речи в затрудненных условиях позволил выявить некоторые тенденции и уточнить ряд особенностей восприятия (в том числе смыслового) материалов различного вида. Полученные результаты не окончательны и требуют проведения дальнейших исследований в этой области. Можно говорить о следующих возможных направлениях изучения звучащего материала: определение и уточнение факторов, влияющих на продуцируемые тексты; совершенствование многоаспектных методов анализа [Потапова, Потапов, 2014]; оценка влияния голоса и речи дикторов на восприятие; оценка перцептивно-слуховых и интеллектуальных возможностей аудиторов, специфики предлагаемого материала, влияющих на его восприятие, и др. Такие исследования станут значительным вкладом в разработку комплексной методики восприятия спонтанных речевых сообщений.

\section{СПИСОК ЛИТЕРАТУРЫ}

Абрамов, Ю. В. Анализ результатов прослушивания фонограмм в шумах с учетом степени информативности / Ю. В. Абрамов, Р. К. Потапова, М. В. Хитина // XVII сессия Российского акустического общества и Сессия научного совета РАН по акустике : сб. тр. Т. 3 : Акустика речи. Медицинская и биологическая акустика. - М. : ГЕОС, 2010а. C. 15-18.

Абрамов, Ю. В. Создание устно-речевой базы данных (УРБД) спонтанных речевых сообщений (на материале русского языка) / Ю. В. Абрамов, Р. К. Потапова, М. В. Хитина, А. В. Маслов, Н. В. Бобров // XVII сессия Российского акустического общества и Сессия научного совета РАН по акустике : сб. тр. Т. 3 : Акустика речи. Медицинская и биологическая акустика. - М. : ГЕОС, 2010б. - С. 91-94.

Абрамов, Ю. В. Специфика смыслового восприятия спонтанного звучащего текста (в условиях эскалации уровня шума) / Ю. В. Абрамов, Р. К. Потапова, М. В. Хитина // Сессия научного совета РАН 
по акустике и XXIV сессия Российского Акустического общества : сб. тр. науч. конф. Т. 3 : Акустика речи. Медицинская и биологическая акустика. Архитектурная и строительная акустика. Шумы и вибрация. - М. : ГЕОС, 2011. - С. 40-45.

Гудков, Н. А. Особенности определения темы текста, воспринимаемого в условиях помех / Н. А. Гудков // Collegium Linguisticum 2016 : материалы ежегод. конф. студен. науч. о-ва МГЛУ. M. : PEMA, 2016. - C. 61-66.

Дридзе, Т. М. Текст как иерархия коммуникативных программ (информативно-целевой подход) / Т. М. Дридзе // Смысловое восприятие речевого сообщения (в условиях массовой коммуникации). М. : Наука, 1976. - С. 48-57.

Потапова, Р. К. Зависимость перцептивнослухового извлечения смысла текста от видов речевой деятельности (в условиях шума) / Р. К. Потапова, М. В. Хитина // Вестник Московского государственного лингвистического университета. 2015. - Вып. 1 (712). - С. 187-196.

Потапова, Р. К. Исследование перцептивнослухового восприятия звучащих текстов в затрудненных условиях / Р. К. Потапова, В. В. Потапов, М. В. Хитина // XVII сессия Российского акустического общества и Сессия научного совета РАН по акустике : сб. тр. Т. 3 : Акустика речи. Медицинская и биологическая акустика. - М. : ГЕОС, 2010а. C. 19-22.

Потапова, Р. К. Исследование перцептивнослухового восприятия звучащих текстов в затрудненных условиях / Р. К. Потапова, В. В. Потапов, М. В. Хитина // Речевые технологии. -2010б. -№ 3. C. 8-14.

Потапова, Р. К. К опыту смыслового восприятия звучащей речи в условиях акустического шума / Р. К. Потапова, В. В. Потапов, М. В. Хитина // Речевые технологии. - 2010в. - № 2. - С. 3-18.

Потапова, Р. К. Теоретические основы нового подхода к реконструкции смыслового контента зашумленной русской речи / Р. К. Потапова, В. В. Потапов // Русский язык: исторические судьбы и современность : тр. и материалы V Междунар. конгр. - М. : Изд-во Моск. ун-та, 2014. - С. 577.

Потапова, Р. К. Экспериментальное исследование возможности определения темы текста в затрудненных условиях / Р. К. Потапова, В. В. Потапов, М. В. Хитина // Сессия научного совета РАН по акустике и XXIV сессия Российского Акустического общества : сб. тр. науч. конф. Т. 3 : Акустика речи. Медицинская и биологическая акустика. Архитектурная и строительная акустика. Шумы и вибрация. - М. : ГЕОС, 2011. - С. 8-12.

Саакян, В. Л. Особенности смыслового восприятия темы монологического текста / В. Л. Саакян // Вестник Московского государственного лингвис- тического университета. - 2014. - Вып. 13 (699). C. 215-223.

Хитина, М. В. Исследование смысловой организации восстановленных текстов монологов в розовом шуме / М. В. Хитина // Вестник Московского государственного лингвистического университета. - 2014. - Вып. 13 (699). - С. 245-254.

Хитина, М. В. Тема текста (дискурса) и методы ее исследования / М. В. Хитина // Речевая коммуникация в информационном пространстве. М. : ЛЕНАНД, 2017. - С. 103-109.

Хитина, М. В. Экспериментальное исследование оценки качества смыслового восприятия спонтанного монолога на фоне аддитивных шумов / М. В. Хитина // Вестник Московского государственного лингвистического университета. - 2012. Вып. 13(646). - С. 198-210.

Хитина, М. В. Экспериментальное исследование смыслового восприятия звучащих текстов / М. В. Хитина // Человек ощущающий: перцепция в современном гуманитарном знании. - М. : ИНИОН РАН, 2015а. - С. 143-151.

Хитина, М. В. Экспериментальное исследование смыслового восприятия и понимания речевого сообщения / М. В. Хитина // Структурная метафизика языка и феноменология речевого дискурса: критерии системных интерпретаций. - М. : Международные отношения, 2015б. - С. 658-667.

\section{REFERENCES}

Abramov Yu.V., Potapova R.K., Khitina M.V. Analiz rezultatov proslushivaniya fonogramm $\mathrm{V}$ shumakh s uchetom stepeni informativnosti [Analysis of the Results of Listening to Phonograms in Noise Taking into Account the Degree of Informativeness]. XVII sessiya Rossiyskogo akusticheskogo obshchestva i Sessiya nauchnogo soveta RAN po akustike: sb. tr. T. 3: Akustika rechi. Meditsinskaya i biologicheskaya akustika $\left[17^{\text {th }}\right.$ Session of the Russian Acoustical Society and the Session of the Scientific Council of the Russian Academy of Sciences on Acoustics: Collected Works. Vol. 3: Speech Acoustics. Medical and Biological Acoustics]. Moscow, GEOS Publ., 2010a, pp. 15-18.

Abramov Yu.V., Potapova R.K., Khitina M.V., Maslov A.V., Bobrov N.V. Sozdanie ustno-rechevoy bazy dannykh (URBD) spontannykh rechevykh soobshcheniy (na materiale russkogo yazyka) [Creation of an Oral-Speech Database (URBD) for Spontaneous Speech Messages (on the Material of the Russian Language)]. XVII sessiya Rossiyskogo akusticheskogo obshchestva i Sessiya nauchnogo soveta RAN po akustike: sb. tr. T. 3: Akustika rechi. Meditsinskaya $i$ biologicheskaya akustika $\left[17^{\text {th }}\right.$ Session of the Russian Acoustical Society and the 
Session of the Scientific Council of the Russian Academy of Sciences on Acoustics: Collected Works. Vol. 3: Speech Acoustics. Medical and Biological Acoustics]. Moscow, GEOS Publ., 2010b, pp. 91-94.

Abramov Yu.V., Potapova R.K., Khitina M.V. Spetsifika smyslovogo vospriyatiya spontannogo zvuchashchego teksta (v usloviyakh eskalatsii urovnya shuma) [Specificity of Sense Perception of a Spontaneous Sounding Text (in the Conditions of Escalating Noise Level)]. Sessiya nauchnogo soveta RAN po akustike i XXIV sessiya Rossiyskogo Akusticheskogo obshchestva : sb. tr. nauch. konf. T. 3: Akustika rechi. Meditsinskaya i biologicheskaya akustika. Arkhitekturnaya i stroitelnaya akustika. Shumy $i$ vibratsiya [Session of the Scientific Council of the Russian Academy of Sciences on Acoustics and the $24^{\text {th }}$ Session of the Russian Acoustical Society: Proceedings of the Scientific Conference. Vol. 3: Speech Acoustics. Medical and Biological Acoustics. Architectural and Building Acoustics. Noises and Vibration]. Moscow, GEOS Publ., 2011, pp. 40-45.

Gudkov N.A. Osobennosti opredeleniya temy teksta, vosprinimaemogo v usloviyakh pomekh [The Features of Defining the Theme of the Text Perceived in the Conditions of Interference]. Collegium Linguisticum 2016. Materialy ezhegod. konf. studen. nauch. o-va MGLU [Collegium Linguisticum 2016. Materials of the Annual Conference of Student Scientific Society of the Moscow State University of Linguistics]. Moscow, REMA Publ., 2016, pp. 61-66.

Dridze T.M. Tekst kak ierarkhiya kommunikativnykh programm (informativno-tselevoy podkhod) [Text as a Hierarchy of Communicative Programs (Information-Targeted Approach)]. Smyslovoe vospriyatie rechevogo soobshcheniya (v usloviyakh massovoy kommunikatsii) [Semantic Perception of Speech Communication (in the Conditions of Mass Communication)]. Moscow, Nauka Publ., 1976, pp. 48-57.

Potapova R.K., Khitina M.V. Zavisimost pertseptivno-slukhovogo izvlecheniya smysla teksta ot vidov rechevoy deyatelnosti (v usloviyakh shuma) [Dependence of Perceptive-Auditory Extraction of Text Meaning on the Types of Speech Activity (under Noise Conditions)]. Vestnik Moskovskogo gosudarst-vennogo lingvisticheskogo universiteta, 2015, iss. 1 (712), pp. 187-196.

Potapova R.K., Potapov V.V., Khitina M.V. Issledovanie pertseptivno-slukhovogo vospriyatiya zvuchashchikh tekstov v zatrudnennykh usloviyakh [Research of Perceptual-Auditory Perception of Sounding Texts in Difficult Conditions]. XVII sessiya Rossiyskogo akusticheskogo obshchestva i Sessiya nauchnogo soveta RAN po akustike: sb. tr. T. 3: Akustika rechi. Meditsinskaya i biologicheskaya akustika $\left[17^{\text {th }}\right.$ Session of the Russian Acoustical
Society and the Session of the Scientific Council of the Russian Academy of Sciences on Acoustics: Collected Works. Vol. 3: Speech Acoustics. Medical and Biological Acoustics]. Moscow, GEOS Publ., 2010a, pp. 19-22.

Potapova R.K., Potapov V.V., Khitina M.V. Issledovanie pertseptivno-slukhovogo vospriyatiya zvuchashchikh tekstov v zatrudnennykh usloviyakh [Investigation of Perceptual-Auditory Perception of Sounding Texts in Difficult Conditions]. Rechevye tekhnologii, 2010b, no. 3, pp. 8-14.

Potapova R.K., Potapov V.V., Khitina M.V. K opytu smyslovogo vospriyatiya zvuchashchey rechi $\mathrm{v}$ usloviyakh akusticheskogo shuma [To Experience of Semantic Perception of Sounding Speech in Conditions of Acoustic Noise]. Rechevye tekhnologii, 2010c, no. 2, pp. 3-18.

Potapova R.K., Potapov V.V. Teoreticheskie osnovy novogo podkhoda $\mathrm{k}$ rekonstruktsii smyslovogo kontenta zashumlennoy russkoy rechi [Theoretical Foundations of a New Approach to the Reconstruction of Semantic Content of Noisy Russian Speech]. Russkiy yazyk: istoricheskie sudby i sovremennost: tr. i materialy VMezhdunar. kongr. [The Russian Language: Historical Destinies and the Present: Proceedings and Materials of the $5^{\text {th }}$ International Congress]. Moscow, Izd-vo Moscovskogo un-ta, 2014, p. 577.

Potapova R.K., Potapov V.V., Khitina M.V. Eksperimentalnoe issledovanie vozmozhnosti opredeleniya temy teksta $\mathrm{v}$ zatrudnennykh usloviyakh [Experimental Study of the Possibility of Determining the Text Theme in Difficult Conditions]. Sessiya nauchnogo soveta RAN po akustike i XXIV sessiya Rossiyskogo Akusticheskogo obshchestva: sb. tr. nauch. konf. T. 3: Akustika rechi. Meditsinskaya i biologicheskaya akustika. Arkhitekturnaya i stroitelnaya akustika. Shumy $i$ vibratsiya [Session of the Scientific Council of the Russian Academy of Sciences on Acoustics and the $24^{\text {th }}$ Session of the Russian Acoustical Society: the Proceedings of Scientific Conference. Vol. 3: Speech Acoustics. Medical and Biological Acoustics. Architectural and Building Acoustics. Noises and vibration]. Moscow, GEOS Publ., 2011, pp. 8-12.

Sakhakyan V.L. Osobennosti smyslovogo vospriyatiya temy monologicheskogo teksta [Features of the Semantic Perception of Monological Texts Theme]. Vestnik Moskovskogo gosudarstvennogo lingvisticheskogo universiteta, 2014, iss. 13 (699), pp. 215-223.

Khitina M.V. Issledovanie smyslovoy organizatsii vosstanovlennykh tekstov monologov v rozovom shume [Investigation of the Semantic Organization of the Restored Texts of Monologues in Pink Noise]. Vestnik Moskovskogo gosudarstvennogo lingvisticheskogo universiteta, 2014, iss. 13 (699), pp. 245-254. 
Khitina M.V. Tema teksta (diskursa) i metody ee issledovaniya [The Theme of the Text (Discourse) and the Methods of Its Research]. Rechevaya kommunikatsiya $v$ informatsionnom prostranstve [Speech Communication in the Information Space]. Moscow, LENAND Publ., 2017, pp. 103-109.

Khitina M.V. Eksperimentalnoe issledovanie otsenki kachestva smyslovogo vospriyatiya spontannogo monologa na fone additivnykh shumov [An Experimental Study of Estimating the Quality of Sense Perception of a Spontaneous Monologue against the Background of Additive Noise]. Vestnik Moskovskogo gosudarstvennogo lingvisticheskogo universiteta, 2012, iss. 13 (646), pp. 198-210.

Khitina M.V. Eksperimentalnoe issledovanie smyslovogo vospriyatiya zvuchashchikh tekstov
[Experimental Study of the Semantic Perception of Sounding Texts]. Chelovek oshchushchayushchiy: pertseptsiya $v$ sovremennom gumanitarnom znanii [A Sensing Person: Perception in Modern Humanities Knowledge]. Moscow, INION RAS Publ., 2015a, pp. 143-151.

Khitina M.V. Eksperimentalnoe issledovanie smyslovogo vospriyatiya i ponimaniya rechevogo soobshcheniya [Experimental Study of Semantic Perception and Understanding of Speech Communication]. Strukturnaya metafizika yazyka $i$ fenomenologiya rechevogo diskursa: kriterii sistemnykh interpretatsiy [Structural Metaphysics of Language and Phenomenology of Speech Discourse: Criteria of System Interpretations]. Moscow, Mezhdunarodnye otnosheniya Publ., 2015b, pp. 658-667.

\section{Information About the Author}

Marina V. Khitina, Doctor of Sciences (Philology), Associate Professor, Professor, Department of Applied and Experimental Linguistics, Moscow State Linguistic University, Ostozhenka St., 38, 1, 119034 Moscow, Russian Federation, khitina49@mail.ru, http://orcid.org/0000-0001-8418-6196.

\section{Информация об авторе}

Марина Викторовна Хитина, доктор филологических наук, доцент, профессор кафедры прикладной и экспериментальной лингвистики, Московский государственный лингвистический университет, ул. Остоженка, 38, стр. 1, 119034 г. Москва, Российская Федерация, khitina49@mail.ru, http://orcid.org/0000-0001-8418-6196. 